\title{
American University Libraries,
}

\section{I95 5-2005}

Dr. McMullen is associate professor of library science, Indiana University.

$\mathrm{E}$ VERY RESPONSIBLE OFFICER in an American university library is constantly making guesses about the future of his institution; every decision he makes should be predicated on one or more of these guesses. Yet he has almost nowhere to turn when he searches for information about the future. The only reliable guides to future events are the navigators' ephemerides. But they are of no use to a librarian unless he still follows the ways of the astrologers, and is able to relate the movements of the heavenly bodies to the changes that will take place in such earthly bodies as the student body, the faculty, or the board of trustees of his university.

The purpose of the present article is not to supply this much needed information about the future of university libraries in so many words but rather, first, to suggest three simple rules about the physical environment conducive to good guessing about the future; second, to name some principles that may serve as channels for thinking about the future; and third, to present a few guesses about the history of American university libraries during the next 50 years. These guesses have been made to give the reader practice in modifying or demolishing them.

The three rules about environment may seem obvious to some librarians, but others may violate them regularly with complete impunity. The first rule is that all guessing should be done in one's office. The how-tostudy experts agree that high school and college students should have a regular place to study because that place will acquire connotations of productive thought. In the same way, a librarian can think about the future of his institution to best advantage if he does his thinking at the same desk where he is accustomed to think about the institution's present and past.

The second environmental rule is concerned with the time of day that is appropriate for a session of guessing. Thinking of this kind should always be done at night, when the only distractions are the visits of janitors or mice. During the day one's colleagues interrupt the train of thought, and, what is much worse, these colleagues are likely to be severely disturbed if they see one thinking. Nothing can be worse for morale than the knowledge that the boss sits at his desk and stares into space.

The third rule may be useful to those who do not use dictating machines. One should use pencil and paper while thinking about the future, but should make notes only infrequently. A person should make notes because without them, he may easily lose even his most brilliant ideas. He should be sparing because each note will be more valuable if it represents a conclusion reached after several possibilities have been considered and rejected. For some people, it is easier to revise or reject a thought before it has been committeed to paper.

Now for some principles that may help to keep the thinker moving in the right direc- 
tion when he considers the future of his library or of university libraries in general.

The first of these principles is that $l i$ braries have, in the past, behaved in some ways like similar social institutions; therefore they probably will behave like them in the future. The trick in applying this rule is in knowing which other social institutions are really similar to libraries, and to get hold of precise information about their behavior. It is unlikely that librarians will benefit by attempting to make use of the grand patterns which men like Spengler, Toynbee, and Sorokin have developed to explain the rise and fall of civilizations. However, it is quite probable that certain discoveries about less extensive social phenomena can be used in prediction about libraries. Louis $\mathrm{N}$. Ridenour in Bibliography in an Age of Science has already demonstrated the striking similarities between the growth of large American research collections, as indicated by the number of volumes, and the growth of other relatively new and useful phenomena as indicated by the growth in assets of life insurance companies, the increase in automobile registrations, and the increase in airline passenger-miles traveled in this country. It is quite possible that imaginative research workers could use these similarities as an aid in piotting the future course of groups of libraries.

Another characteristic of certain social institutions which may have application to libraries is expressed, but not explained, by the "rank-size rule." If all cities and towns in the United States are ranked in order of size, and the rank of each (counting New York City as I, the next smaller as 2, etc.) is multiplied by its population, the products obtained will be significantly similar. Social scientists do not know why this is so.

Many groups of social institutions seem to follow the same pattern quite closely, and still others follow it to some extent. For example, if large retail firms of the United
States are ranked according to gross sales, the products of the ranks times the sales in dollars are sufficiently similar to indicate some relationship. This rule and its possible implications are discussed in the summer, 1952, issue of the UNESCO publication, Impact of Science on Society, in an article by John Q. Stewart. Do all libraries in the United States follow the rank-size rule? Do university libraries? Closely or to some extent? Why?

A second principle to guide a librarian in thinking about his library is that, while it is true that libraries are prone to behave like other types of organizations which are in some ways similar to them, it must also be remembered that a library is the kind of institution that may be directly affected by changes taking place outside itself.

Some of these external changes are easily recognized, but others can go unnoticed for years. It is easy to see the close connection between the financial support of a university library and the economic status of its parent institution, and many of the dislocations made by wars are painfully clear, but a librarian may fail to observe the changes in his collection that are brought about by less tangible forces such as the gradual changes in the basic beliefs of scholars in a certain discipline. For example, librarians sometimes are unaware that the usefulness of older materials in the area of literary and artistic history and criticism is being diminished by the current movement away from a somewhat relativistic, comparative, and subjective state of mind toward a greater dependence on objective standards for artistic judgments.

Sometimes a librarian may even fail to notice important changes in educational practices in his own institution. If the head of the Economics Department makes use of the set of matched luggage that the faculty gives him at the dinner celebrating his retirement, then long rows of ancient journals 
may never leave their shelves. If the vigorous new head of the same department soon imports faculty members who enjoy forcing graduate students to scramble around in government documents and reports of business firms, the library may need an additional staff member who knows how to make the students' scrambling more nearly worth the time it takes.

A third principle which we sometimes ignore is that different trends are of greatly varying lengths. A trend that has begun in the last few years may fade out sooner than does an older one that started many years ago. In fact, it is almost certain that some trends now in existence will soon die and that other trends will begin to move in the opposite direction.

One of these reversals of direction which may be taking place now in the university library field is to be seen in practices connected with the storage of books. In the latter part of the nineteenth century, a combination of circumstances brought about the general acceptance of the multi-level stack in preference to the older plan of shelving books in alcoves around the reading room. The present trend in university library buildings toward the interspersing of stacks with small reading areas will bring back the close contact which the alcove provided between readers and books.

The decreased opportunity for intercourse between the librarians and the youthful occupants of the seats may raise problems in those coeducational institutions where the dormitory parlors are insufficient to seat the socially inclined young men and women. Such problems are said to have existed in the days of alcoves, and they became noticeably less acute when reading rooms of a later time provided an unobstructed view from the librarian's desk.

A fourth principle that one should consider in guessing about the future is never to mix this guessing process with two related processes, planning and wishful thinking. Planning should take place after guessing, and of course wishful thinking should be avoided entirely.

People who plan without first guessing about trends, or who dream of a better future without any careful planning, are inclined to ignore one of the few really obvious facts that can be learned from the study of library history: as present problems are solved in the future, or as they eventually die of old age, others will rise to take their places. During the next 50 years, university librarians will be busy solving problems that are not yet even gleams in the eyes of the students, faculty, or publishers.

There is still another principle which the would-be prognosticator must consider: the rate and direction of change will vary greatly from institution to institution.

It seems probable that a person summarizing the state of American university libraries in the year 2005 will find his task as arduous as does a writer in 1955 because many libraries will be atypical. It is within the realm of probability that some libraries will not have reached, in particular aspects, a state of development which has already been reached by others in 1955. We may be sure that the laggards will be able to cover their lack of progress with the statement that has already proved its worth by 1955 , "Our reasons for doing it this way are historical."

Now for some predictions about the future of American university libraries. The following guesses have been made under the circumstances prescribed in the three environmental rules stated at the beginning of this article, and an attempt has been made to abide by the five principles that followed the rules. However, the predictions may be far from the mark because their accuracy depends also on the writer's knowledge of recent library history and his native intelligence. If they stir anyone to refute them, 
they will have served a large part of their purpose.

If we pay any attention whatsoever to our second principle, the one that says a library is quickly affected by changes taking place outside itself, then we should speculate about the next 50 years in universities as a whole before we think about the libraries which live within them.

By the year 2005, the student body in many a university may no longer be so sharply divided into undergraduate and graduate segments. It is probable that progressive universities will offer many more degrees than they do now. If a student leaves school at any time between his second and eighth year of residence, he will receive a diploma of some sort indicating the amount and kind of work he has done. The faculties in these more progressive universities will have long ceased to argue over the relative merits of general, special, and vocational education because they will recognize the importance of the individual differences between students. They will know that each student's pattern of courses must vary from every other student's pattern, but they will fill their learned journals with arguments over the relative merits of various systems for discovering each student's needs. Faculties in the more conservative institutions will profess to find all of this very confusing and will fill other learned journals with witty attacks on the whole idea of progressive higher education.

Faculties may disagree about the efficacy of progressive higher education in the year 2005, but students will line up wholeheartedly on the side of the conservatives. They will all say that the thorough testing and counseling programs in some institutions leave them no privacy whatever. They will long for the good old days before the effects of a gala weekend were evident to one's adviser during the following three depth interviews. Students will sigh also for the days before "flexible scholarships," the monstrous arrangements whereby the amount paid to the recipient is directly and precisely proportional to the quality of his work. In short, it seems likely that many American university students in 2005 will make intensive use of libraries, but two of their main reasons will be that if they fail to do so their counselors will soon know it and their incomes will soon drop.

Although changes in the habits of students will have noteworthy effects on the characteristics of American university libraries in the next 50 years, changes in the research habits of the faculty will probably cause more profound alterations in library collections and services. The most noticeable of the broader changes will be the increasing use of scholars in the humanities of methods of investigation that, before the I950's and 60's, had been used almost exclusively in the natural and social sciences. It seems likely that more students of music, art, and literature will be inclined to count items and that some of the bolder spirits will even attempt to control the conditions of experiments. This tendency toward the statistical treatment of artistic material may mean that libraries will have to possess many more items in these fields than they now do. However, it is probable that for many types of investigations, lists or reproductions will suffice. Perhaps iconographies, lists of copyright entries and biobibliographical compendia will become more popular with scholars.

Another research trend may appear to some extent in all fields of learning and may have a marked effect on the nature of university collections before 2005. It is quite possible that scholars generally will become less interested in studying the production of ideas, and will expand their present interest in the consumption of ideas by the various "publics."

Along with the development of this con- 
cern about the consumers of literary, artistic, scientific, or social ideas will come an increased attention to the middlemaneditors, popularizers, anthologists, book reviewers, booksellers, producers of educational motion pictures, museum directors, librarians, and whatnot-who chop the raw fruits of genius and arrange them in salads that are both attractive to the eye and easy to swallow. Perhaps the historian of science in 2005 will accord as many paragraphs to E. E. Slosson or Bruce Bliven as to scientists who have been making memorable discoveries in recent years.

If more and more scholars begin to study the distribution and consumption of intellectual products, then university libraries will need to overhaul their acquisition policies in several ways. Just as some library administrators in 1955 wish that the predecessors had collected dime novels and mailorder catalogs, so in 2005, may others wish that their professional ancestors had acquired at least a representative sampling of comic books, paper-backed reprints, and television kinescopes.

What of the people and devices that will attempt to control these collections and make them useful? First, the head librarian. Fifty years from now he will still be the key individual among those whose ideas are of importance to the development of the library, but he will feel that those above and below him in the hierarchy are slowly hemming him in. If the university library becomes more and more vital to the university, as it is quite likely to become, then presidents and deans will concern themselves more and more with library affairs, leaving fewer opportunities for the librarian to make sweeping policy decisions. If American clerical and intellectual workers continue to organize themselves into more complex social and professional patterns, then staff associations and ad hoc staff committees may play a larger part in the management of the in- ternal affairs of the library.

University library administrators will cry on each other's shoulders when they discuss their narrowing area of responsibility, but the more discerning among them will feel that, as their role has changed from that of commander to that of coordinator, the new challenges have not prevented them from making substantial contributions to the wellbeing of their institutions.

The increasing need on the part of the library administrator to work in close cooperation with university officials and library staff members will have one beneficial result: he will no longer be able to choose between being either a bookman or an administrator. He will have to be a very knowledgeable bookman to keep the respect of deans, department heads, and the like, and he will have to use all of the wiles known to business management if he is to keep his staff from taking over all responsibility for the operation of the library.

If the staff of the university library of the future comes to play a more important part in policy making, it will surely need to develop techniques to reduce the cost per hour of group activity. When all committee meetings are recorded for sound and sight, staff members will be careful to make fewer irrelevant remarks and will absolutely never take unsightly snoozes at the conference table.

It is unlikely that the typical university library staff of 2005 will employ any mechanical devices which are not already in existence in 1955. There will be three reasons for this apparent lack of future progress: (I) recently developed instruments such as indexers, transmitters, translators, and copying devices may require many years before they are developed to the stage where they can be economically used in a variety of libraries; (2) some entirely new instruments will be invented during the next 50 years,

(Continued on page 295) 
tof the library collection. Every attempt will be made to keep the terminology and form of this subject analysis in line with cataloging principles wherever possible. The responsibility of the library will be to follow the work of the staff member, to confer on choice of terms and to provide links from the subject catalog to the analysis file, or if the analytics are put into the central catalog, to see that they are edited and integrated into the main subject index.

We feel that a recognition of the complexity of the problem at hand is crucial to its solution-though not its solution. When several specialists have an important stake in the successful solution of a problem, a meeting of the minds, a willingness to understand one another's difficulties, to permit a flexibility in established procedures all combine to set the stage for this vitally important operation. It is no longer feasible merely to entertain expectations. Discussions around a conference table from time to time between library staff and program staff can do more than anything else to maintain the important respect and cooperation which will ensure the success of the program and the growth of the library as the repository of its major collections of research materials.

\section{American University Libraries, 1955-2005}

\section{(Continued from page 29o)}

but they quite probably will still be so expensive in 2005 that only a few libraries will be able to afford them; (3) there may be a limit to the amount of speed and efficiency faculty members will accept.

Librarians will not approve of this apparent backwardness on the part of scholars, but it will be the result of habits of thought which are hard to change. If a man is going to spend a period of six months to six years in producing a piece of research, it cannot make much difference to him if the librarian is able to assemble and to present him with the materials he needs within a period of two days instead of a period of two weeks.

It might be worthwhile to turn to some of the less mechanical weapons employed by university library staffs in fighting the battle for bibliographical control of facts and ideas. If card catalogs grow much in size, they will surely be broken in pieces; some have already lost sizable chunks. Will these breaks follow subject lines, format or language lines, or lines that divide the books according to date of publication? Will the catalog some day describe only those materials not described in printed bibliographies? Guesses about the future of the weapons to be used in bibliographical warfare could easily make a book in themselves.

The present discussion should come to a stop before it, too, becomes a book. Let it close, however, with the expression of a hope that librarians will not allow their guessing about the future to stop as books do, but will extend it indefinitely, in the manner of the healthier serials. 